\title{
Epidemiological study of the prevalence of depressive disorders in primary health care in Morocco
}

\author{
Bouchra Oneib, Maria Sabir ${ }^{1}$, Naima Abda ${ }^{2}$, Abderazak Ouanass ${ }^{1}$ \\ Department of Psychiatry, Faculty of Medicine, Mohammed I University, Oujda, ${ }^{1}$ Department of Psychiatry, Faculty of Medicine, Mohammed V University, \\ Rabat, ${ }^{2}$ Department of Epidemiology Faculty of Medicine, Mohammed I University, Oujda, Morocco
}

\begin{abstract}
Objective: To determine the prevalence and the impact of depressive disorders in primary health care and its associated factors. Methodology: It's a cross-sectional study with 351 participants selected from Moroccan primary care facilities, aged above 18 years without chronic somatic or psychiatric disease. The participants answered a questionnaire that included demographic characteristics, the Mini International Neuropsychiatric Interview for major depressive episode (MDE), dysthymic disorder and the Global Assessment of Functioning (GAF). Statistical analysis was performed by the SPSS 13.0 software. Results: The prevalence of depressive disorders in the sample was $13.7 \%$, that of MDE was $9.1 \%$, while dysthymic disorder was $4.3 \%$, the rate of recurrent depressive episodes was $38.2 \%$ ( $6 \%$ of participants), and the prevalence of depression over a lifetime was $17.7 \%$. The percentage of depression was higher among women than men $(P=0.01) \cdot 6.3 \%$ of depressed patients have already attempted to suicide. Analysis of GAF scores showed an average of $76.2 \pm 24$, a lower score was significantly found among patients with current MDE $(P=0.001)$, dysthymic subjects $(P=0.001)$ and those who suffer from recurrent MDE $(P=0.001)$. Depressive disorders in univariate analysis were associated with: Female gender $P=0.01$ odds ratio $(\mathrm{OR}) 2.1$ (1.09-4.3), unemployment $P=0.02 \mathrm{OR} 0.4$ (o.2-0.9), and childbearing age $P=0.004$ OR 3.5 (1.5-8). Adjusted OR has not demonstrated a significant association. Conclusion: The high prevalence of depressive disorders, suicide risk, and the alteration of the quality of life among primary health care patients in Morocco suggest the importance of identifying and treating this population.
\end{abstract}

Key words: Associated factors, depressive disorders, Morocco, prevalence, primary health care

\section{Introduction}

Depressive disorders are within the most prevalent mental disease worldwide.$^{[1,2]}$ According to an epidemiological study of affective disorders in the USA, the prevalence of major depressive disorder for a lifetime was $16.2 \%$, ${ }^{[3]}$ while in Morocco, a national survey conducted in 2005 showed a prevalence of $26.5 \%$ in the general population. ${ }^{[4]}$

We know that $40-50 \%$ of depressed patients are detected in primary health care, and $20 \%$ receive adequate

\section{Address for correspondence:}

Dr. Bouchra Oneib, Department of Psychiatry,

University Psychiatric Center Mohammed VI, 60020 Oujda, Morocco.

E-mail: boucha82@hotmail.com

\begin{tabular}{|l|l|}
\hline \multicolumn{2}{|c|}{ Access this article online } \\
\hline Quick Response Code: & Website: \\
\hline & www.ruralneuropractice.com \\
\cline { 2 - 2 } & \\
\hline
\end{tabular}

treatment. ${ }^{[5]}$ Early diagnosis can improve well-being of patients, ensure a better antidepressant response and reduce the risk of recurrence and suicide. ${ }^{[6,7]}$

The objective of the study is to determine the prevalence and the impact life of depressive disorders in primary health care and its associated factors.

\section{Methodology}

\section{Study sample and procedure}

This is a cross-sectional study over 2 years from 2012 to 2014, on a sample of Moroccan consultants in primary health care in two cities.

This is an open access article distributed under the terms of the Creative Commons Attribution-NonCommercial-ShareAlike 3.0 License, which allows others to remix, tweak, and build upon the work non-commercially, as long as the author is credited and the new creations are licensed under the identical terms.

For reprints contact: reprints@medknow.com

How to cite this article: Oneib B, Sabir M, Abda N, Ouanass A. Epidemiological study of the prevalence of depressive disorders in primary health care in Morocco. J Neurosci Rural Pract 2015;6:477-80. 
The sample size was calculated using the following formula:

$\mathrm{N}=1,96^{2} \mathrm{p} \cdot(1-\mathrm{p}) /$ margin of error ${ }^{2}$

With:

- $\mathrm{p}$ : The expected proportion of subjects presented a depression

- Margin error: Between 0,032 and $0.05^{2}$

The patients must be aged 18 years old or more. We excluded subjects who were treated for a psychiatric disorder and/or chronic and disabling physical illness such as diabetes, endocrine disorders, neurological disorders, cancer, and others. We also excluded the subjects who refused to participate in the study, and those who have not given their verbal consent.

Data collection was carried out by psychiatrist and physicians who received psychiatric training for the Mini International Neuropsychiatric Interview (MINI). It was conducted using a standardized questionnaire with two parts.

The first part assesses the demographic characteristics of consultants; the socioeconomic level of the participants; and physiological status of women. To determine the socioeconomic level of the participants, we used the scale "The Problems Meeting Basic Needs," which include five items specifying, in the last 30 days, if the participants met with serious problems regarding basic specified encompassing food, transportation, finance, shelter, and clothing. ${ }^{[8]}$ Among women, we specified the childbearing status.

The second part used the MINI, to assess major depressive episode (MDE) (current and anterior), depressive episode with melancholic features, dysthymic disorder, and suicide risk. The MINI has been translated and validated in Moroccan dialect; ${ }^{[9]}$ the validity study demonstrated a satisfactory quantitative assessment of the value of kappa $>0.8$. We assessed also the quality of life by "Global Assessment of Functioning" (GAF) which is a numerical scale (from 0 to 100) used to evaluate the psychological, social and professional performances of an individual. The research communities affirmed that the reliability of the scale GAF is good specifically when it is used in patients with a mood disorder. ${ }^{[10]}$

The time spent to evaluate each participant by the questionnaire was $30 \mathrm{~min}$.

\section{Statistical analysis}

Statistical analysis was performed by The Statistical
Package for the Social Sciences (SPSS) version 13.0 software provided by the laboratory of Biostatistics, faculty of medicine Rabat. A descriptive analysis of the different parameters was made. Quantitative variables were described as a means \pm standard deviation and categorical variables were expressed as percentages. A search for factors associated with depressive disorders was made using the Chi-square test or Student's $t$-test. Then logistic regression was used to take into account possible confounding factor. A $P<0.05$ was considered significant.

\section{Results}

The sample was composed of 351 patients, 211 (60\%) of women and $140(40 \%)$ of men. About 181 (85.5\%) women were in reproductive age. A significant age difference was observed $(P=0.0001)$ between men $(40 \pm 16.7)$ and women, $(36.5 \pm 12)$ [Table 1].

The prevalence of depressive disorders was 13.7\%, MDE and dysthymia are more common among women than men $(P=0.0001, P=0.05$, respectively) [Table 2].

The melancholic features were found among 22, $6 \%$ of depressive patients and $6.3 \%$ of these patients have already attempted to suicide.

Table 1: Sociodemographic characteristics

\begin{tabular}{lc}
\hline Characteristics & $\boldsymbol{n}(\%)$ \\
\hline Age (years) & $37.9 \pm 14(36.5-39.5)^{\star}$ \\
Gender & $140(40)$ \\
$\quad$ Man & $211(60)$ \\
Women & \\
Profession & $120(34.2)$ \\
$\quad$ With & $231(65.8)$ \\
$\quad$ Without & \\
Marital status & $135(38.5)$ \\
Lives alone & $216(61.5)$ \\
Couple & \\
Level of education & $60(17.1)$ \\
Unschooled & $291(82.9)$ \\
Schooled & \\
Socioeconomic level & $161(45.9)$ \\
Low & $190(54.1)$ \\
Medium & *
\end{tabular}

${ }^{*}$ Means \pm SD (Cl). SD: Standard deviation, Cl: Confidence interval

Table 2: Prevalence of depressive disorders

\begin{tabular}{lc}
\hline Disorder & $\boldsymbol{n}(\%)$ \\
\hline MDE & $32(9.1)$ \\
Dysthymia & $15(4.3)$ \\
Recurrent MDE & $21(6)$ \\
Depression over a lifetime & $62(17.7)$ \\
\hline
\end{tabular}

MDE: Major depressive episode 
The prevalence of MDE in men who have attempted to suicide was $16.7 \%$ versus $2.8 \%$ among women without a statistically significant difference $(P=0,2)$.

Results of the general GAF score showed an average of $76.25 \pm 24$, a lower score was found in patients with current $\operatorname{MDE}(P=0.0001)$, dysthymic subjects $(P=0.0001)$ and those who suffered from recurrent $\operatorname{MDE}(P=0.0001)$ [Table 3].

The univariate analysis reveals that the MDE was associated with the following variables: Female gender $P=0.01$ odds ratio (OR) 2.1 (1.09-4.3), unemployment $P=0.02$ OR $0.4(0.2-0.9)$, and child-bearing age $P=0.004$ OR 3.5 (1.5-8), whereas this association was not significant according to multivariate analysis [Table 4].

\section{Discussion}

Depressive disorders have a negative influence on the quality of life of patients and their professional competence. ${ }^{[11,12]}$ This disease also is known by its suicide risk. Indeed, $16 \%$ of depressed patients died by suicide. ${ }^{[13,14]}$

In clinical practice, the first contact with these patients will be at the primary care. ${ }^{[15]}$ However, identifying patients with depressive symptoms can be difficult for the primary care physicians due to the diversity of depressive spectrum. ${ }^{[16,17]}$

Our study showed that depressive disorders are common in primary care, and depressed patients have a disrupted social and professional functioning.

\section{Table 3: Quality of life}

\begin{tabular}{lc}
\hline & GAF scale \\
\hline Patients without depressive disorders & $90 \pm 0^{*}$ \\
Patients with depressive disorders & $75.9 \pm 24(68.8-83)$ \\
MDE & $65.8 \pm 22(57.6-74)$ \\
Dysthymia & $97.4 \pm 6(93-100)$ \\
Recurrent MDE & $56 \pm 21(46.3-65.6)$ \\
\hline${ }^{*}$ Means \pm SD (CI). MDE: Major depressive episode, SD: Standard deviation, \\
GAF: Global Assessment of Functioning
\end{tabular}

Table 4: Regression logistic

\begin{tabular}{lcc}
\hline & \multicolumn{2}{c}{ OR (95\% Cl) } \\
\cline { 2 - 3 } & Univariate & Multivariate \\
\hline Age & $1.01(0.9-1.03)$ & $2.6(0.9-7.8)$ \\
Gender & $2.1(1.09-4.3)$ & $1.3(0.5-3)$ \\
Profession & $0.4(0.2-0.9)$ & $0.5(0.2-1.3)$ \\
Level of education & $1.7(0.8-3.6)$ & $1.5(0.6-3.3)$ \\
Physiological status & $3.5(1.5-8)$ & $2.6(0.9-7.8)$ \\
\hline OR: Odds ratio, Cl: Confidence interval
\end{tabular}

According to our results, $13.7 \%$ of patients in primary care meet the criteria of Diagnostic and Statistical Manual of Mental Disorders IV of depressive disorders. This prevalence is lower than that found in other studies where the prevalence was between $22.6 \%$ and $30.3 \% .{ }^{[18-20]}$

In the present study, $9.1 \%$ of patients had an MDE, a prevalence lower than that some previous studies, ${ }^{[1,21]}$ but much higher than others conducted in the general population..$^{[3,22-24]}$ Such disparity can be explained by the difference in methodological assessment of depressive disorders.

In addition, $4.3 \%$ subjects screened had a dysthymia, a rate similar to that found in Spanish study. ${ }^{[25]}$

Analysis of data confirmed the high rate of prevalence of lifetime of depression ( $17.7 \%$ ) this seems closer to the results of two American studies. ${ }^{[22,26]}$

A gender difference in the prevalence of depressive disorders was observed $P=0.01$ OR 2.1 (1.09-4.3). In fact, women have a higher rate of MDE and dysthymia compared to men; which consistent with the literature. ${ }^{[27]}$

Our finding indicated that the GAF score was statistically significant lower among patients with depressive disorders, specifically patients with MDE and recurrent MDE. In a cross-sectional study evaluated the quality of life among 360 depressed patients; ${ }^{[28]}$ they found that the score is altered in all its physical and mental dimensions. A second study, ${ }^{[29]}$ carried out in China revealed that $<3 \%$ of depressed outpatients are satisfied with their health. Other studies and meta-analysis showed that depressive disorders are an important determinant of disability and quality of life in patients. ${ }^{[30,31]}$

On multivariate analysis, we did not find a significant association this can be explained by the sample size, which was relatively smaller than that of other studies. Although it has been demonstrated that MDE was associated with female gender, substance use, unmarried status, and being unemployed. ${ }^{[23,32]}$

\section{Conclusion}

The prevalence of depressive disorders, suicide risk, and the alteration of the quality of life among primary health care patients in Morocco, suggest the importance of identifying and treating this population, which implies the physician awareness of those disorders.

\section{Financial support and sponsorship Nil.}




\section{Conflicts of interest}

There are no conflicts of interest.

\section{References}

1. Ansseau M, Dierick M, Buntinkx F, Cnockaert P, De Smedt J, Van Den Haute M, et al. High prevalence of mental disorders in primary care. J Affect Disord 2004;78:49-55.

2. Craven MA, Bland R. Depression in primary care: Current and future challenges. Can J Psychiatry 2013;58:442-8.

3. Kessler RC, Berglund P, Demler O, Jin R, Koretz D, Merikangas KR, et al. The epidemiology of major depressive disorder: Results from the National Comorbidity Survey Replication (NCS-R). JAMA 2003;289:3095-105.

4. Moussaoui D. Mental health in Morocco, national survey on the prevalence of mental disorders and drug addiction. Encephale 2007;33:125-6.

5. Mitchell AJ, Rao S, Vaze A. Do primary care physicians have particular difficulty identifying late-life depression? A meta-analysis stratified by age. Psychother Psychosom 2010;79:285-94.

6. Bukh JD, Bock C, Vinberg M, Kessing LV. The effect of prolonged duration of untreated depression on antidepressant treatment outcome. J Affect Disord 2013;145:42-8.

7. Volicer L, Frijters DH, van der Steen JT. Underdiagnosis and undertreatment of depression in nursing home residents. Eur Geriatr Med 2011;2:332-7.

8. Plant EA, Sachs-Ericsson N. Racial and ethnic differences in depression: The roles of social support and meeting basic needs. J Consult Clin Psychol 2004;72:41-52.

9. Kadri N, Agoub M, El Gnaoui S, Alami KH, Hergueta T, Moussaoui D. Moroccan colloquial Arabic version of the Mini International Neuropsychiatric Interview (MINI): Qualitative and quantitative validation. Eur Psychiatry 2005;20:193-5.

10. Ramirez A, Ekselius L, Ramklint M. Axis V - Global Assessment of Functioning scale $(\mathrm{GAF})$, further evaluation of the self-report version. Eur Psychiatry 2008;23:575-9.

11. Greenberg PE, Kessler RC, Birnbaum HG, Leong SA, Lowe SW, Berglund PA, et al. The economic burden of depression in the United States: How did it change between 1990 and 2000? J Clin Psychiatry 2003;64:1465-75.

12. Barry LC, Allore HG, Bruce ML, Gill TM. Longitudinal association between depressive symptoms and disability burden among older persons. J Gerontol A Biol Sci Med Sci 2009;64:1325-32.

13. Harwood D, Hawton K, Hope T, Jacoby R. Psychiatric disorder and personality factors associated with suicide in older people: A descriptive and case-control study. Int J Geriatr Psychiatry 2001;16:155-65.

14. Wulsin LR, Vaillant GE, Wells VE. A systematic review of the mortality of depression. Psychosom Med 1999;61:6-17.

15. King M, Nazareth I, Levy G, Walker C, Morris R, Weich S, et al. Prevalence of common mental disorders in general practice attendees across Europe. Br J Psychiatry 2008;192:362-7.

16. Zuithoff NP, Vergouwe Y, King M, Nazareth I, Hak E, Moons KG, et al. A clinical prediction rule for detecting major depressive disorder in primary care: The PREDICT-NL study. Fam Pract 2009;26:241-50.

17. Louch P, Goodman C, Greenhaigh T. Involving service users in the evaluation and redesign of primary care services for depression: A qualitative study. Prim Care Community Psychiatr 2006;10:109-17.

18. Coyne JC, Fechner-Bates S, Schwenk TL. Prevalence, nature, and comorbidity of depressive disorders in primary care. Gen Hosp Psychiatry 1994;16:267-76.

19. Mergl R, Seidscheck I, Allgaier AK, Möller HJ, Hegerl U, Henkel V. Depressive, anxiety, and somatoform disorders in primary care: Prevalence and recognition. Depress Anxiety 2007;24:185-95.

20. Udedi M. The prevalence of depression among patients and its detection by primary health care workers at Matawale Health Centre (Zomba). Malawi Med J 2014;26:34-7.

21. Serrano-Blanco A, Palao DJ, Luciano JV, Pinto-Meza A, Luján L, Fernández A, et al. Prevalence of mental disorders in primary care: Results from the diagnosis and treatment of mental disorders in primary care study (DASMAP). Soc Psychiatry Psychiatr Epidemiol 2010;45:201-10.

22. Kessler RC, Chiu WT, Demler O, Merikangas KR, Walters EE. Prevalence, severity, and comorbidity of 12-month DSM-IV disorders in the National Comorbidity Survey Replication. Arch Gen Psychiatry 2005;62:617-27.

23. Wittchen HU, Jacobi F, Rehm J, Gustavsson A, Svensson M, Jönsson B, et al. The size and burden of mental disorders and other disorders of the brain in Europe 2010. Eur Neuropsychopharmacol 2011;21:655-79.

24. Rancans E, Vrublevska J, Snikere S, Koroleva I, Trapencieris M. The point prevalence of depression and associated sociodemographic correlates in the general population of Latvia. J Affect Disord 2014;156:104-10.

25. Aragonès E, Piñol JL, Labad A, Masdéu RM, Pino M, Cervera J. Prevalence and determinants of depressive disorders in primary care practice in Spain. Int J Psychiatry Med 2004;34:21-35.

26. Barry KL, Fleming MF, Manwell LB, Copeland LA, Appel S. Prevalence of and factors associated with current and lifetime depression in older adult primary care patients. Fam Med 1998;30:366-71.

27. Hanel G, Henningsen P, Herzog W, Sauer N, Schaefert R, Szecsenyi J, et al. Depression, anxiety, and somatoform disorders: Vague or distinct categories in primary care? Results from a large cross-sectional study. J Psychosom Res 2009;67:189-97.

28. Hadj Ammar M, Khammouma S, Nasr M. Depressive disorders and quality of life: A cross sectional study including 360 depressive patients followed at the psychiatry consultation of the Mahdia university hospital. Encephale 2008;34:256-62.

29. Zeng Q, Xu Y, Chun Wang W. Quality of life in outpatients with depression in China. J Affect Disord 2013;150:513-21.

30. Alonso J, Angermeyer MC, Bernert S, Bruffaerts R, Brugha TS, Bryson $\mathrm{H}$, et al. Disability and quality of life impact of mental disorders in Europe: Results from the European Study of the Epidemiology of Mental Disorders (ESEMeD) project. Acta Psychiatr Scand Supp 2004;11:38-46.

31. Rapaport MH, Clary C, Fayyad R, Endicott J. Quality-of-life impairment in depressive and anxiety disorders. Am J Psychiatry 2005;162:1171-8.

32. Milanovic SM, Erjavec K, Poljicanin T, Vrabec B, Brecic P. Prevalence of depression symptoms and associated socio-demographic factors in primary health care patients. Psychiatr Danub 2015;27:31-7. 